\title{
Red de Facultades de Odontología
}

Como ya lo señalaba hace varios años Josep Xercavins i Valls "si en la oscuridad y dificultad analítica actual hubiera que asociar con una sola palabra y un solo concepto -y aunque sobre ellos también haya aún mucha oscuridadla caracterización de la gran revolución, en la que estaríamos inmersos, de las formas de vida de la humanidad en el planeta Tierra y de la nueva realidad civilizatoria que con ella se estaría alumbrando, entonces, ciertamente, la palabra sería globalización y el concepto, en principio, mundo global’”.

En esa línea de pensamiento, la Facultad de Odontología de la Universidad Nacional del Nordeste, ha impulsado enérgicamente el fortalecimiento de las relaciones con sus pares de la región y del mundo, en el convencimiento de que para avanzar en la calidad académica, del posgrado, de la investigación, y de la gestión en sí misma considerada, deben compartirse y socializarse las experiencias con otras instituciones de educación superior, nacionales y extranjeras, estableciendo un feed-back que nos permita la mejora permanente.

Una de las herramientas más eficientes y eficaces para operar colaborativamente en la actualidad, es el trabajo en redes y consorcios en el marco de los cuales se generan espacios de análisis, discusión y flujo recíproco de experiencias entre las instituciones integrantes.

En ese sentido, nuestra Facultad de Odontología, se propuso un objetivo claro y concreto, en el sentido de promover la creación de la "Red de Facultades de Odontología de la Región MERCOSUR”, con el acompañamiento de las Facultades de Odontología de la Universidad Nacional de Rosario (Argentina), la Universidad Federal de Rio Grande do Sul (Brasil), la Universidad de la República (Uruguay) y la Universidad Nacional de Asunción (Paraguay).

\footnotetext{
I XERCAVINS I VALLS, Josep: "La Educación superior y las Instituciones de Educación Superior ante una crisis paradigmático-civilizatoria: Reflexiones, análisis y elementos propositivos desde un foro de organizaciones internacionales de la sociedad civil", en "La Educación Superior en el Mundo -3- Educación Superior: Nuevos retos y roles emergentes para el desarrollo humano y social", GUNI, Ed. Mundi-Prensa, año 2008 , p.38.
} 
Dicha red, tiene como meta fundamental, constituirse en un espacio integrado de de cooperación, intercambio de buenas prácticas y reflexión en materia de internacionalización de las actividades académicas, de investigación, de extensión y vinculación y transferencia tecnológica, específicamente en el área de la salud bucal.

Se ha sembrado, de este modo, una semilla que anhelamos haga crecer un árbol de relaciones interinstitucionales entre las Facultades de Odontología de la Región MERCOSUR, del cual deriven frutos que beneficien a toda nuestra comunidad académica y científica.

Mgter Sergio Junior Shwoihort Asesor Área Cooperación Internacional

Facultad de Odontología. UNNE 